\title{
Adult Respiratory Distress Syndrome, CTCAE
}

National Cancer Institute

\section{Source}

National Cancer Institute. Adult Respiratory Distress Syndrome, CT CAE. NCI Thesaurus. Code C58020.

A disorder characterized by progressive and life-threatening pulmonary distress in the absence of an underlying pulmonary condition, usually following major trauma or surgery. 